\title{
3D modelling of beach topography changes caused by the tombolo phenomenon using terrestrial laser scanning (TLS) and unmanned aerial vehicle (UAV) photogrammetry on the example of the city of Sopot
}

\author{
Cezary Specht ${ }^{1}$ (D) - Pawel S. Dabrowski ${ }^{1}$ (D) $\cdot$ Mariusz Specht $^{2}$ (D)
}

Received: 22 April 2020 / Accepted: 8 June 2020 / Published online: 17 June 2020

(C) The Author(s) 2020

\begin{abstract}
In 2011, a yacht marina was built in Sopot (the largest holiday resort in Poland), which initiated the formation of a local shallowing of the bottom related to the tombolo effect. The building of the marina led to disturbances in the transmission of bottom deposits along the coast, which resulted from waves and the shift of the beach coastline by approx. $50 \mathrm{~m}$ towards the sea. Its effects include progressive morphological changes in the shore and the sea bottom, which will lead to the formation of a peninsula between the shore and the marina in the future. This paper presents the results of a comparative analysis of the accuracy of 3D modelling of the tombolo phenomenon in the onshore part of the beach using both point clouds obtained by terrestrial laser scanning methods and photogrammetric methods based on unmanned aerial vehicle photographs. The methods subjected to assessment include both those for land modelling and for determining the coastline course and its changes. The analysis results prove the existence of sub-metre differences in the imaged relief and the coastline course, which were demonstrated using an analysis of land cross-sections. The possibilities and limitations of both methods are demonstrated as well.
\end{abstract}

\section{Introduction}

Sopot is one of the major Polish holiday and spa resorts situated on the coast of the Baltic Sea. The city has the longest wooden pier in Europe, which is regularly damaged by storms. In October 2009, a violent storm completely destroyed the wooden structure of the pier groyne. The only economically viable method for protecting the pier was to build two breakwaters from the eastern and southern side (Fig. 1). The basin bordered between these breakwaters and the pier groyne

Pawel S. Dabrowski

p.dabrowski@wn.umg.edu.pl

Cezary Specht

c.specht@wn.umg.edu.pl

Mariusz Specht

m.specht@wn.umg.edu.pl

1 Department of Geodesy and Oceanography, Gdynia Maritime University, Gdynia, Poland

2 Department of Transport and Logistics, Gdynia Maritime University, Gdynia, Poland and head has become the natural marina (Mayor of the City of Sopot n.d.). Expert discussions and their opinions resulted in a decision to build a yacht marina in Sopot ( 3 basins, a maximum of 103 vessels: 40 large ones, up to $14 \mathrm{~m}$ in length, and 63 boats up to $10 \mathrm{~m}$ in length) for PLN 72 million. The seemingly undoubted decision is currently becoming a serious problem for the city, as the building of the marina led to the local inhibition of the transport of debris (sand) along the coast, which resulted in its accumulation between the marina and the shore and the shift of the coastline towards the sea (approx. $-50 \mathrm{~m}$ ), and initiated the process of inevitable formation of a peninsula in Sopot. Such an oceanographic phenomenon known as a tombolo (Ahmed 1997) is most frequently influenced by the course of beaches and coasts under natural conditions but can also result from human activities, as is the case in Sopot (The Institute of Oceanology of the Polish Academy of Sciences 2016). In the Bay of Gdańsk, the strongest surface wind waves are generated from direction E towards W. The waves that reach the beach in Sopot from the East, hitting diagonally against the shore, cause the movement of bottom sediments along the coast. After the marina was built, its breakwater significantly decreased the wave energy; moreover, waves are deflected at both ends (Fig. 1b), which 


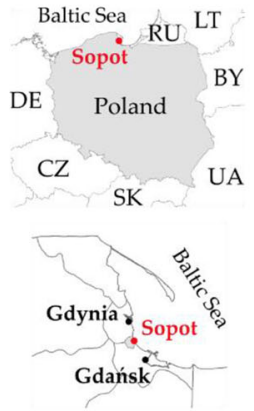

a)

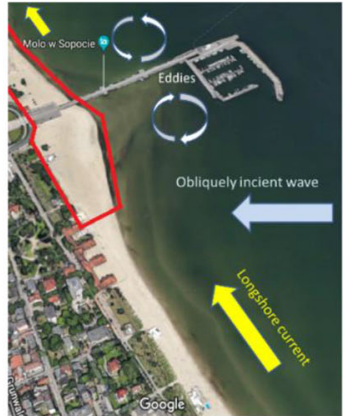

b)

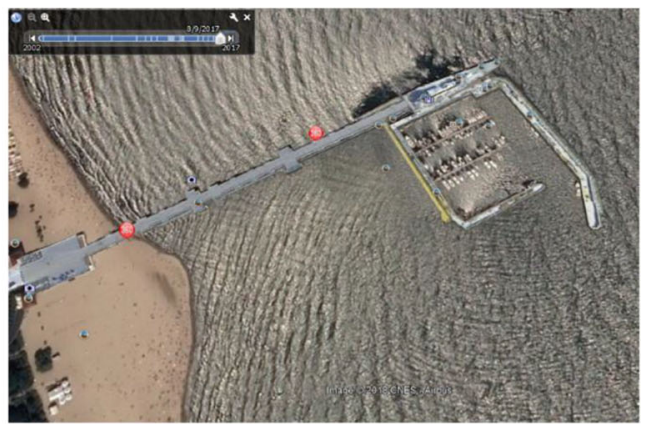

c)

breakwater in Sopot (c). Red polygon (b) represents a part of survey area. Sources and dates of the images: Google Maps, 05.05.2019 (b); Google Earth, 09.08.2017 (c)

such areas as, e.g. precision agriculture, forestry, cryology, or geology. The generation of point clouds from photographs involves the application of the structure-from-motion (SfM) processing chain (Nesbit and Hugenholtz 2019). A research on shoreline variability is also carried out using another type of technology — mobile laser scanning (Donker et al. 2018).

One of the numerous areas which require 3D modelling of the relief is seaside area. In terms of maritime economy activities, the areas of beaches directly adjacent to the coastline are of particular significance. In geospatial terms, their monitoring is justified by the high rate of its changes caused primarily by oceanographic factors. The course of beaches and the coastline has a significant impact on the broadly understood management of the land zone adjacent to the coast line and has an effect on the safety of maritime transport and navigation (Urbanski et al. 2008) as well as hydro-engineering and harbour structures. A particularly important aspect in terms of international law is the course of the territorial sea baseline, which determines the maritime borders of a country (Specht and Specht 2018). Apart from technical aspects of the measurement performance, the issue requires the application of GNSS network methods associated with their proper selection, (Specht et al. 2017c). Moreover, it is worth noting that the coastline, in terms of international law, does not delimit the borders of the territorial sea of countries, which enable the transition from ellipsoid heights determined by GNSS receivers to the system of orthometric and normal heights (Dabrowski 2019). This is of particular importance for the establishment of international height systems based on the adopted reference level, which are used as the state height systems in many countries (Ihde et al. 2000).

Considering the above aspect, the comparative analysis of terrestrial laser scanning and unmanned aerial vehicle methods should preferably be presented with wide, extended beaches as an example. The beach width feature indicates the possibility for both performing the measurement and appropriate numerical operations and comparing the results originating from two types of instruments. On the other hand, the 
linear course of the beach enables the observation of the coastline determined using both methods. Hence, the beach in Sopot (Poland), whose characteristics satisfy the above requirements, was selected as the research area. The independently conducted laser and photogrammetric measurements allowed the obtained results to be comparatively analysed. Despite the fact that nowadays in many cases photogrammetric missions are carried out using ground control points (GCPs), in the research, a point cloud generated without using them was used. In the light of the literature analysis, the authors noted that this method of creating digital surface models is not a topic often addressed by researchers in publications. Despite the lowered accuracy of the point cloud created without GCPs, this method is relatively popular due to reduced amount of survey work, equipment, and time involved. Therefore, the conclusions from the analysis may be important not only for the experienced surveyors but also for nonprofessional UAV users. Noteworthy is the publication (James et al. 2019), whose authors presented a proposal for guidelines that should be guided by, among others, contractors for photogrammetric missions.

\section{Materials and methods}

The analysis of the tombolo phenomenon covers an $800 \times$ $200 \mathrm{~m}$ area. Two advanced measuring methods were employed to determine the relief of a part of the beach in Sopot. The first of them is terrestrial laser scanning with the advantage of mass acquisition of spatial data which determine the surroundings of the instrument. The limitation of the method is the possibility for recording data on objects located within both the scanner's field of view and the range characteristic of a particular instrument. Thus, measuring a more complex structure or a greater area of land requires the establishment of a number of measurement sites. The second of the applied techniques is a flying drone and the photogrammetric development of land cover models. Based on the sequence of photographs taken at a specific flight pass altitude, their spatial orientation is performed, which subsequently allows the coordinates of particular points to be read and a colour to be assigned to them. The limitation of the method is a lower accuracy resulting from the errors of the aircraft positioning system (often only GPS), inaccuracy of the data acquisition method, and the quality of the mounted camera.

\section{Terrestrial laser scanning}

In recent years, terrestrial laser scanning has been increasingly common in Poland. Manufacturers place subsequent models on the market, which are characterised by increasingly better accuracy and performance parameters. In terms of land surveying inventory measurement performance, their particular significance was emphasised through the relevant legal status. The definition of the implementing act describes the measurement procedure, which involves the determination of threedimensional coordinates of points based on two (horizontal and vertical) angles and the distance measured by the electromagnetic method (Heritage and Large 2009). The very high measurement efficiency is reflected in the measurement of hundreds of thousands and even a million points per second (Vosselman and Maas 2010), and results in the formation of very large sets of measured points. These sets, commonly referred to as point clouds, are a numerical representation of the environment surrounding a laser scanner. Under office conditions, the spatial configuration of permanent elements measured by the scanner can be reconstructed within the threedimensional space of the software dedicated to this purpose.

A separate issue of the data elaboration process is the determination of the position of the measured and recorded point clouds in relation to the adopted state or global flat coordinate systems and height systems. This process, referred to as georeferencing, involves the determination of coordinates in both systems (primary and secondary). Usually, in order to ensure high reliability of the compilation, precise positioning techniques such as control network-based tachimetry or RTK or RTN correction-supported GNSS satellite measurements are applied. Consequently, the spatial data harmonisation requirement imposed by the European legislation is satisfied (The Act 2010) so the georeferenced TLS clouds can be used in various analyses for both research and official administrative purposes.

\section{Unmanned aerial vehicles and the photogrammetric model}

In view of the increasing trend for the development of technologies involving unmanned aircraft and their increasing availability, they are an alternative to other devices used to acquire information on relief. Photogrammetric compilations are used in many areas of science and industry (FernándezGuisuraga et al. 2018). The majority of aerial drones performing photogrammetric flight passes are based on the multirotor structure and are equipped with a high-resolution digital camera mounted on a special support (gimbal) which enables three-axial rotation of the apparatus within the specified angle range. The photographs obtained from a photogrammetric flight pass are characterised by a high resolution which, in the case of their larger number and where a point cloud is formed from them, necessitates the use of highperformance workstations. A flight pass is performed with the same lighting of the area. This requirement is a certain obstacle to covering larger areas and is a logistical challenge at the measurement planning phase. Another practical problem is the high energy demand of rotor drones which generate aerodynamic lift exclusively by means of propellers. In order to perform a flight pass over a larger area, it is necessary to 
Fig. 2 TLS: the location of laser scanner measurement sites

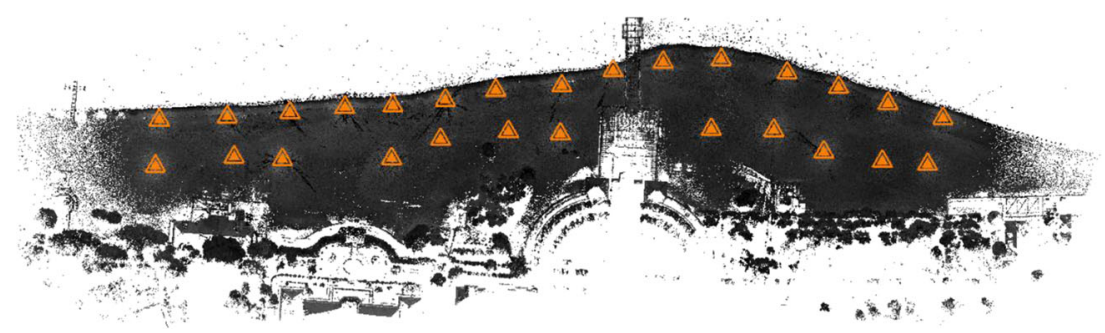

apply breaks at work and to exchange batteries during a photogrammetric mission. The selection of an aircraft flight parameters is directly related to the expected photographic resolution. GSD (ground sampling distance) parameter is one of accuracy criterions for the development of photogrammetric models. This represents the distance in the field between the centres of neighbouring pixels, and for flight passes performed using an unmanned aircraft, it ranges from 1 to $5 \mathrm{~cm} /$ pix. Thus, it defines the maximum accuracy of map projection obtained after processing photographs using photogrammetric software.

\section{Cloud-to-cloud comparison methods}

The sets formed as a result of measurement data processing are independent point clouds. Due to the a priori assumed high accuracy of the resultant point cloud originating from terrestrial scanning and connected by the georeference, it was adopted as a reference value in relation to the point cloud generated from photographs. The procedure of comparing the contents of both sets was followed by applying the Hausdorff distance also referred to as the PompeiuHausdorff distance (Berinde and Pacurar 2013). It assumes the calculation, for each point in the cloud, of a distance from the nearest points of the second cloud. This is followed by the selection of a minimum distance value which defines the separation of a particular point from the point cloud under comparison. Given the high resolution of both sets, the adoption of such an approach is justified and allows conclusions regarding the mutual spatial relations to be drawn.

\section{Measurements}

Terrestrial laser scanning of the beach was performed on October 15, 2018. In view of the elongated surface nature of the object under measurement, it was necessary to plan and arrange an appropriate number of sites. The measurement was taken with a Trimble TX8 laser scanner without the phototaking option. Hence, the obtained point clouds had only colours resulting from the calculated laser beam reflection intensity. To cover the assumed study area, it was necessary to establish 27 sites located at a distance of approx. $60 \mathrm{~m}$ from each other (Fig. 2). In view of the small number of characteristic objects to be used for the recording of a point cloud in the field at a later time, spherical tags located in the sand in a manner ensuring the stability of their position were used. The tags had to be located a relatively short distance from the neighbouring measurement sites; therefore, they were located halfway between them or in their immediate vicinity. Such an approach ensured that a relatively large set of points on the spherical tag's surface were obtained during the measurement. This enabled the precise fitting of spheres into the set of points and the determination of their midpoints which, in the recording process, were the points of adjustment of particular local point cloud systems.
Fig. 3 The area under a flight pass: an orthophotomap (a) and the locations of photographs taken (b). Photographs rejected in the processing are marked in red

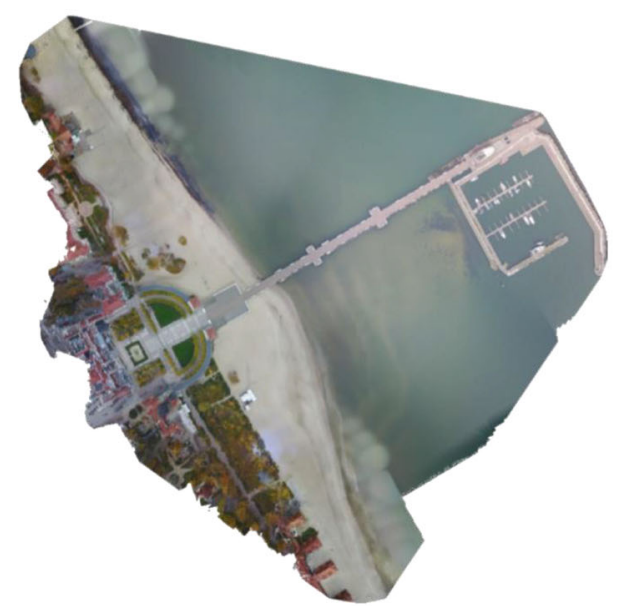

(a)

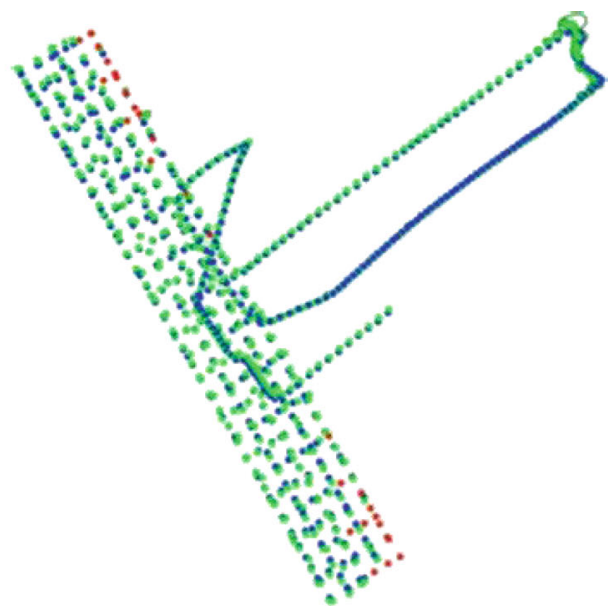

(b) 
Table 1 UAV camera parameters

\begin{tabular}{ll}
\hline Sensor & $1 / 2.3^{\prime \prime}(\mathrm{CMOS}) ;$ effective pixels, $12.35 \mathrm{M}$ (total pixels, $\left.12.71 \mathrm{M}\right)$ \\
Lens & FOV $78.8^{\circ} 28 \mathrm{~mm}(35 \mathrm{~mm}$ format equivalent) $\mathrm{f} / 2.2$ \\
Distortion & $<1.5 \%$ focus from $0.5 \mathrm{~m}$ to $\infty$ \\
ISO range & $100-3200$ (video), $100-1600$ (photo) \\
Shutter speed & $8-1 / 8000 \mathrm{~s}$ \\
Image max size & $4000 \times 3000$ \\
\hline
\end{tabular}

In order to ensure the possibility of referring measurements to the state coordinate systems functioning in Poland, selected spherical tags were measured by the GNSS RTK satellite method based on a network of VRS Net.pl corrections. The error of point coordinate determination in this method usually amounts to approx. $2 \mathrm{~cm}$ in the horizontal plane and $3 \mathrm{~cm}$ in the vertical plane. However, with an advantageous spatial arrangement of satellite constellations and the proximity to the system reference station, accuracies of 1 and $1.5 \mathrm{~cm}$, respectively, are commonly found. Therefore, it can be assumed that the location of points determined in this way enables their adoption as highly reliable reference values.

The second part of the measurements, the UAV mission, was carried out on November 1, 2018. In view of the large area to be covered by an aircraft and the need to obtain the most accurate results, the study area was divided into three parts. Two of them were the beach separated by the Sopot pier, i.e. the third part. The photogrammetric flight pass was performed using a DJI Mavic Pro drone independently for each of the adopted parts. The data were recorded using a Pix4D Capture mobile application. During the mission, 621 photographs were taken at an altitude of $60 \mathrm{~m}$ above the drone take-off level (the beach). The obtained average GSD coefficient value amounted to $2.25 \mathrm{~cm} /$ pix at a camera resolution of $4000 \times 3000$ effective pixels. The overlap parameter defining the degree of photograph overlapping in transverse and longitudinal directions was determined to be $80 \%$. During a $28-\mathrm{min}$ flight pass, the aircraft covered a distance of $7800 \mathrm{~m}$ and covered an area of $0.4 \mathrm{~km}^{2}$ with photographs. Given that the area under the flight pass was partially covered with water, and in view of the high variability of the aqueous environment (waves), a proportion of photographs were automatically rejected during data processing (Fig. 3). Parameters of the drone camera are presented in the Table 1.
For the purpose of comparative analysis, both point clouds (TLS and UAV) were sampled according to the minimum distance between points of $2 \mathrm{~cm}$. As a result of the operation, data sets consisting of 15.713 (UAV) and 22.878 (TLS) million points were obtained.

\section{Data elaboration}

\section{A point cloud from laser scanning and from a photogrammetric model}

The recording of 27 point clouds based on 37 spherical tags located in the sand was characterised by the adjustment error of $2.5 \mathrm{~mm}$. The process was carried out using Trimble Real Works software. The a priori adopted criterion of the terrestrial laser scanning method's high accuracy was therefore numerically confirmed. The second stage of work was to assign coordinates to the measured tags in a flat coordinate system (PL-2000) and in the normal height system. The tags adopted for the measurements were located at extreme positions in the southern west-northern east direction as well as in the central region of the analysed area (Fig. 4).

Georeferencing of the recorded point cloud (with a local system of one of the sites) to the state spatial reference system is carried out, similarly to the recording, by means of the transformation comprising translation, rotation and, optionally, a change in the scale. Since measuring instruments (particularly range-finding modules) are calibrated, the scale change factor is most often equal to unity. Similarly, thanks to the presence of a tilt compensator and a bull's eye and electronic level system in the scanner, it is relatively easy to ensure that the instrument is correctly mounted horizontally on a tripod. Therefore, the sequence of elementary rotations around the

Fig. 4 TLS: the recorded point cloud georeference

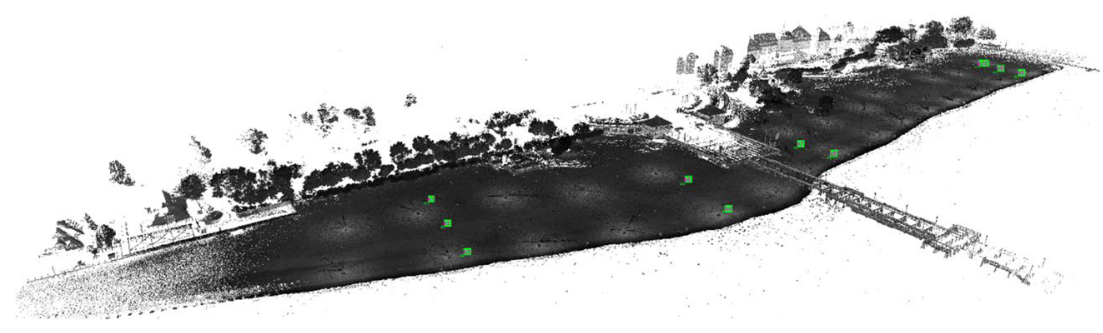




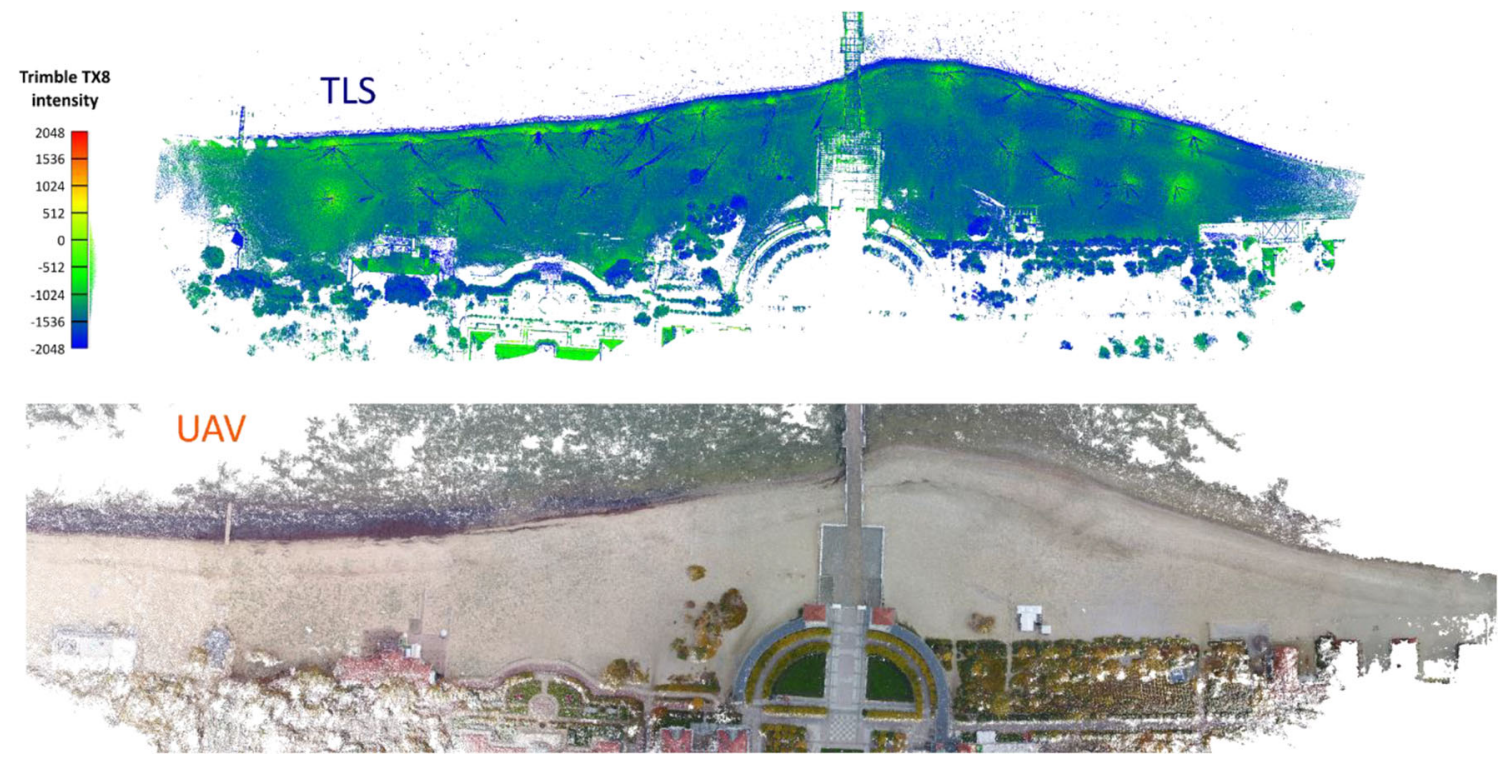

Fig. 5 TLS and UAV: point clouds originating from the measurement using two methods

axis of the local coordinate system is reduced to a single rotation around the vertical axis. The calculations are complemented by the translation of results to consider a vector whose coordinates are determined based on known coordinates measured using the GNSS RTK method. Figure 5 presents the resultant data sets generated on the basis of both adopted measuring methods.

The above spatial operation was verified by independent satellite GNSS RTK measurement, during which the coordinates of several clearly identifiable points were determined.
As control points, the corners of permanent elements of technical infrastructure located in the vicinity of the beach were selected (among others sidewalk corners, mole beams corners, and upper fencing surfaces). After determining the coordinates of the features by the satellite receiver, the corresponding TLS point cloud coordinates were obtained. The comparison confirmed the correctness of the conducted georeferencing. The average value of the difference was $0.04 \mathrm{~m}$ in the horizontal plane $(\mathrm{Hz})$ and $0.02 \mathrm{~m}$ in the vertical direction $(\mathrm{V})$ (Table 2).

Table 2 Verification of TLS cloud point georeferencing

\begin{tabular}{|c|c|c|c|c|c|c|c|c|}
\hline \multirow[t]{2}{*}{ No. } & \multicolumn{3}{|c|}{ GNSS RTK measurement } & \multicolumn{3}{|c|}{ Point cloud measurement } & \multicolumn{2}{|l|}{ Error } \\
\hline & Easting (m) & Northing (m) & Normal height (m) & Easting (m) & Northing (m) & Normal height (m) & $\mathrm{Hz}(\mathrm{m})$ & $\mathrm{V}(\mathrm{m})$ \\
\hline 1 & $6,537,153.84$ & $6,035,081.08$ & 2.86 & $6,537,153.83$ & $6,035,081.07$ & 2.83 & 0.02 & -0.03 \\
\hline 2 & $6,537,152.65$ & $6,035,083.02$ & 2.87 & $6,537,152.66$ & $6,035,082.99$ & 2.83 & 0.03 & -0.04 \\
\hline 3 & $6,537,124.24$ & $6,035,168.95$ & 2.80 & $6,537,124.30$ & $6,035,168.96$ & 2.82 & 0.06 & 0.02 \\
\hline 4 & $6,537,115.85$ & $6,035,183.56$ & 2.81 & $6,537,115.86$ & $6,035,183.58$ & 2.84 & 0.02 & 0.03 \\
\hline 5 & $6,537,102.59$ & $6,035,278.10$ & 2.93 & $6,537,102.62$ & $6,035,278.13$ & 2.98 & 0.04 & 0.05 \\
\hline 6 & $6,537,116.93$ & $6,035,285.94$ & 4.01 & $6,537,116.99$ & $6,035,285.95$ & 4.01 & 0.06 & 0.00 \\
\hline 7 & $6,537,133.98$ & $6,035,312.68$ & 2.86 & $6,537,134.05$ & $6,035,312.67$ & 2.87 & 0.07 & 0.00 \\
\hline 8 & $6,537,152.78$ & $6,035,324.76$ & 2.92 & $6,537,152.84$ & $6,035,324.74$ & 2.92 & 0.07 & 0.00 \\
\hline 9 & $6,537,139.38$ & $6,035,329.65$ & 3.10 & $6,537,139.43$ & $6,035,329.66$ & 3.14 & 0.05 & 0.04 \\
\hline 10 & $6,537,096.78$ & $6,035,323.63$ & 4.03 & $6,537,096.84$ & $6,035,323.66$ & 4.05 & 0.06 & 0.02 \\
\hline 11 & $6,536,925.67$ & $6,035,526.91$ & 1.87 & $6,536,925.65$ & $6,035,526.97$ & 1.85 & 0.06 & -0.03 \\
\hline 12 & $6,536,924.82$ & $6,035,528.69$ & 1.87 & $6,536,924.83$ & $6,035,528.68$ & 1.86 & 0.01 & -0.01 \\
\hline 13 & $6,536,884.73$ & $6,035,654.36$ & 1.08 & $6,536,884.75$ & $6,035,654.31$ & 1.13 & 0.05 & 0.05 \\
\hline 14 & $6,536,904.16$ & $6,035,663.90$ & 1.27 & $6,536,904.16$ & $6,035,663.85$ & 1.30 & 0.04 & 0.03 \\
\hline 15 & $6,536,906.80$ & $6,035,658.40$ & 1.30 & $6,536,906.79$ & $6,035,658.38$ & 1.28 & 0.02 & -0.02 \\
\hline 16 & $6,536,909.31$ & $6,035,659.56$ & 1.27 & $6,536,909.34$ & $6,035,659.55$ & 1.28 & 0.03 & 0.02 \\
\hline
\end{tabular}




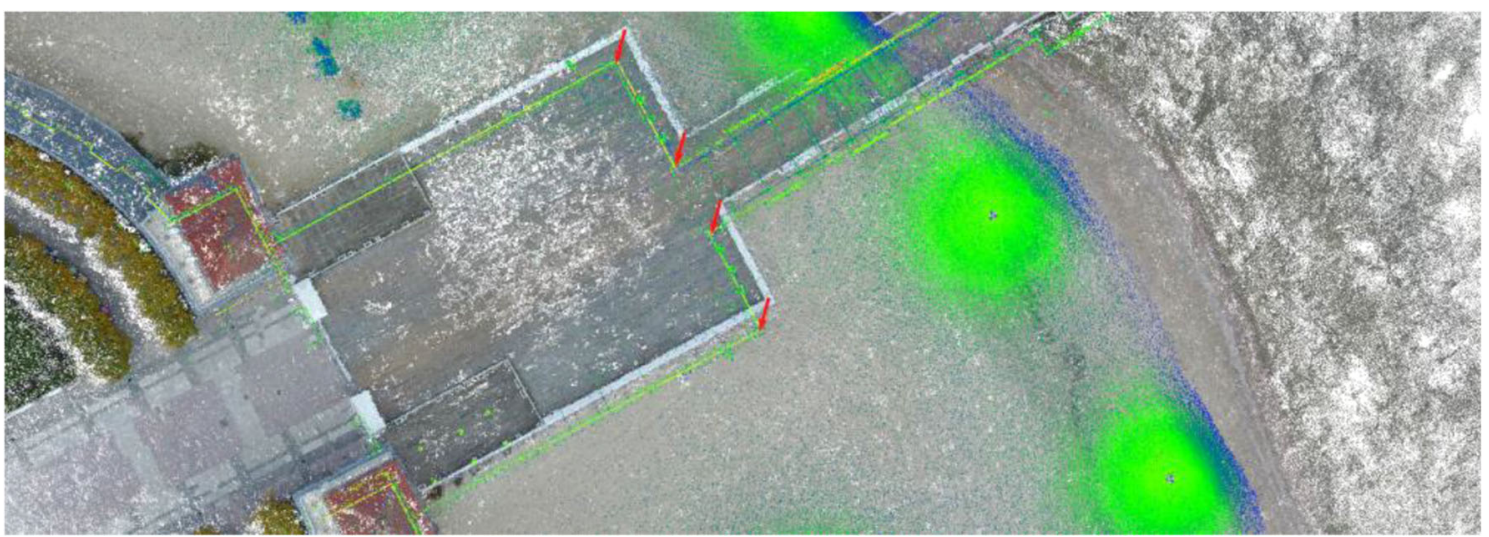

Fig. 6 TLS and UAV: offset in the horizontal XY plane (red vectors). Point clouds colours the same as in Fig. 5

The next stage of work was to narrow down the set of points in the cloud to those representing the beach surface. Depending on the software, the point cloud classification operations may be carried out manually, semi-automatically, or automatically. In the first case, it is the software user's responsibility to properly trim the point cloud and eliminate the undesirable elements. This operation is very labour-intensive and time-consuming. In the present task, an automatic ground-level detection algorithm implemented into the Trimble Real Works software was applied. As a result, a point cloud free of noise and comprising points recorded on the sand surface was obtained.

A photogrammetric model was developed using the Pix $4 \mathrm{~d}$ Mapper Pro software which enables photographic data processing and generating based on three-dimensional models and orthophotomaps. Of the 621 aerial photographs obtained during the flight pass, 586 were used to generate the model, which accounts for $94 \%$ of the entire obtained collection. A median of 21,128 nodal points on a single photograph was obtained, which indicates a relatively high number of characteristic points and areas, considering the frequently little diversified coverage of the area surface. The photograph processing operation resulted in the generation of a cloud containing $20,666,253$ points, which translates into a density of approx. 117 points per $\mathrm{m}^{2}$. Numerical data processing was carried out using a high-parameter workstation (16 GB RAM, i7-6600U, GTX 1070) and lasted for $3 \mathrm{~h} 42 \mathrm{~min}$. The following values of RMS errors for particular coordinates were obtained: $2.83 \mathrm{~m}(\mathrm{x}), 4.08 \mathrm{~m}(\mathrm{y})$, and $9.81 \mathrm{~m}(\mathrm{z})$. The abovementioned numerical characteristics reflect inter alia the accuracy of the GNSS receiver mounted on the drone used. For comparison with more accurate data originating from a laser scanner, georeferencing of the point cloud was carried out at a later stage of calculation work.

\section{Spatial data harmonisation}

Where work is performed on spatial information sets originating from various measuring instruments, the Act (The Act 2010) recommends that data harmonisation (understood as the adjustment of coordinate systems and reference systems) should be carried out to reliably conclude and compare both elements. In the case under consideration, it could be assumed that both spatial references are identical, as georeferencing of the laser scanning point cloud was carried out, and the point cloud originating from a flight pass obtained coordinates based on the GNSS satellite positioning module present on-

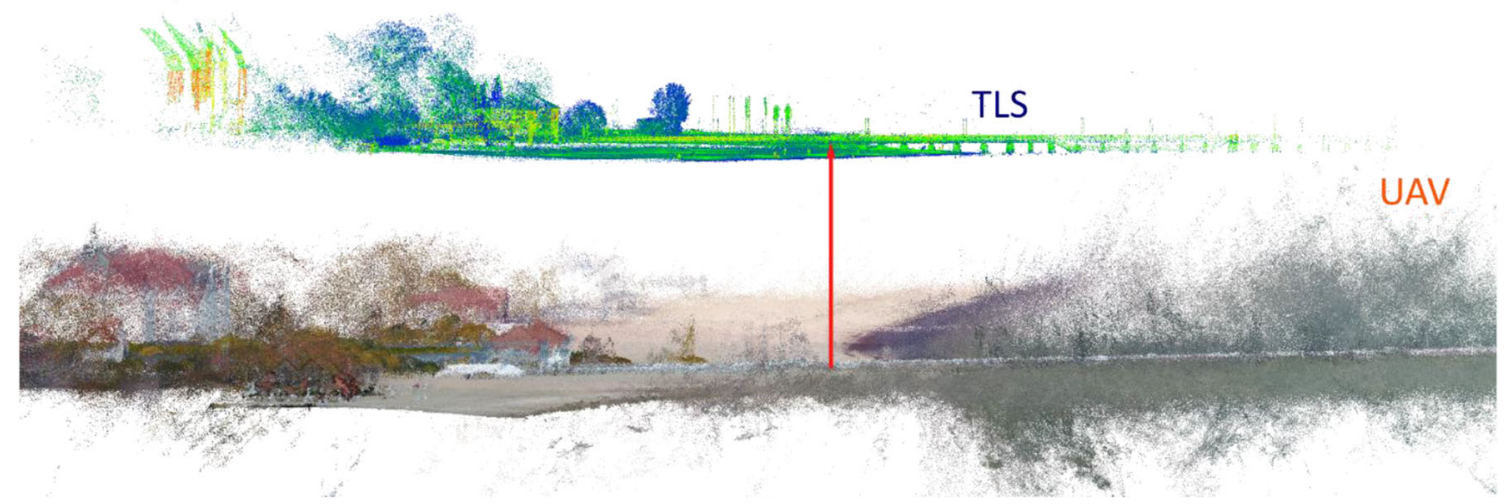

Fig. 7 TLS and UAV: offset in vertical direction Z (red vector). Point clouds colours the same as in Fig. 5 
Table 3 Transformation matrix

\begin{tabular}{llll}
\hline 0.976307153702 & -0.000068962800 & 0.001982993679 & 3.510482788086 \\
0.000042953408 & 0.976225197315 & 0.012802618556 & -8.041839599609 \\
-0.001983727328 & -0.012802504934 & 0.976223230362 & 47.436077117920 \\
0.000000000000 & 0.000000000000 & 0.000000000000 & 1.000000000000 \\
\hline
\end{tabular}

board the flying drone. However, a detailed assessment found the occurrence of significant differences in the spatial orientation of both data sets. The point clouds did not overlap with each other in a horizontal plane (Fig. 6).

The (green and blue) point cloud originating from laser scanning was referenced to the state coordinate system and the state reference system using a highly accurate and reliable GNSS RTK positioning technique. Considering this fact, its georeference was assumed to be true. In Fig. 7, the red arrows indicate the shift of the point cloud originating from a flight pass (RGB colours) in a horizontal plane. The vectors were approx. 4-m long, which may indirectly provide information on the accuracy of the drone's GNSS receiver accuracy. On the other hand, a considerably greater shift of point clouds was noted in the vertical plane (Fig. 7).

In Fig. 7, the red arrow indicates the shift value of approx. $40 \mathrm{~m}$. An approximate value was indicated because, apart from the shifts in a horizontal plane and in vertical direction, the inclination of the point cloud originating from a flight pass (UAV cloud) was noted in relation to the laser scanning reference cloud (the TLS cloud). The reason for this situation may be the failure to use the values of height coordinates of the terrestrial geopotential models which approximate the geoid course in relation to the reference ellipsoid in the calculation. Again, this indicates the accuracy of the drone on-board equipment, in this case the MEMS inertial system. The presence of significant noise within the UAV point cloud is also worth noting (points with coordinates that do not represent any actual field objects).

In view of the noted discrepancies in the location and orientation of point clouds, the UAV point cloud was additionally adjusted in relation to the TLS point cloud. To this end, a uniquely identifiable set of points representing the same points in the field was identified within the space of both point clouds. Thus, the coordinates of points in both coordinate systems were obtained, which provide the basis for the determination of the seven-parameter spatial transformation matrix value (Table 3 ).

The software used for the calculation (CloudCompare) introduces the scale change coefficient to the values defining the rotation and translation. In the case under consideration, the coefficient value of 0.9763 was obtained. This is another indication of the UAV point cloud accuracy. After the transformation was conducted, spatial consistency was obtained for both data sets, which was a prerequisite for the comparison of their accuracy. The obtained differences in the deviations of particular points of the UAV point cloud from the reference TLS cloud were calculated using the Hausdorff distance algorithm. The deviation values are presented in Fig. 8.

\section{A comparison of point clouds}

Despite careful manual filtering of the UAV point cloud and cleaning it of noise, it was still an important factor which needed to be taken into account in calculations. Therefore, the presentation of the maximum single values of deviations of extremely distant points was abandoned. Instead, a 1-m border which characterised the analysed point cloud was empirically determined. The result indicates significant changes in vertical direction. A factor justifying this situation is the fact that the measurements were not carried out at exactly the same time. However, these differences should be found mainly within the Baltic Sea coastline area and in its immediate vicinity. In more distant regions, aeolian and hydrological factors do not affect the variability of the beach relief so significantly. In order to present this phenomenon, four cross-sections were generated which represented sectors of the UAV and TLS point clouds. The location of the cross-sections is presented in Fig. 9.
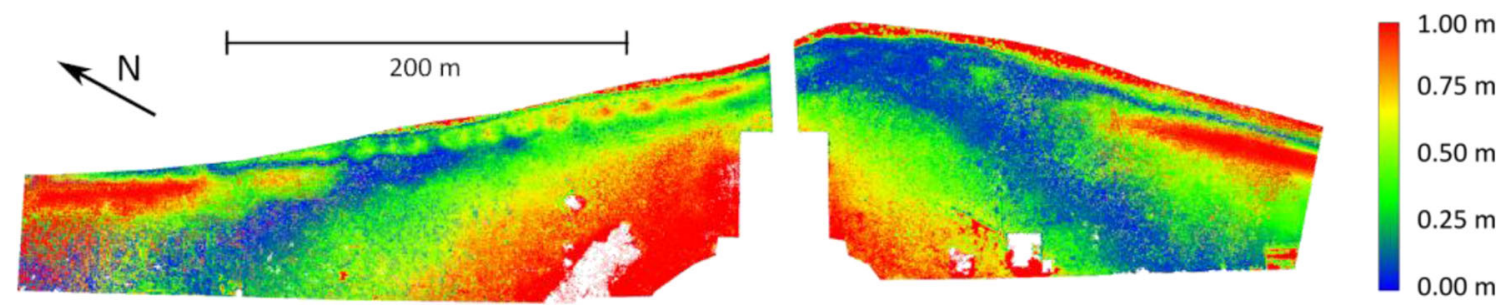

Fig. 8 Cloud-to-cloud difference 


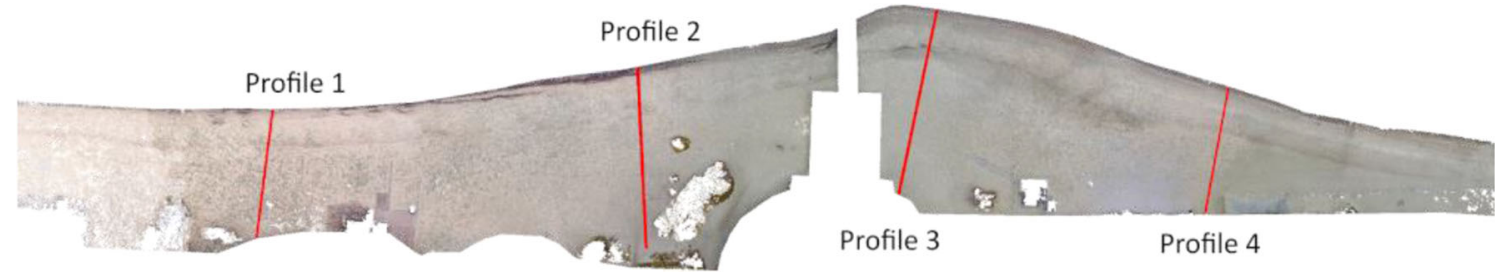

Fig. 9 The course of transverse profiles in the UAV cloud

Two profiles were located at the edge of the TLS point cloud which occupies a slightly smaller area than the UAV cloud constructed on the basis of aerial photographs (compare Fig. 6). The other two profiles were located symmetrically by dividing the area into four parts. The spatial configuration of the points is presented in Fig. 10. To increase the readability, the height coordinate values of the cloud points were doubled.

To present the profile arrangement, orthogonal projection was applied at an angle enabling the simultaneous presentation of all elements. Considering the values of the obtained deviations, which usually do not exceed $1 \mathrm{~m}$ (Fig. 9), the following conclusions can be drawn:

- The extreme profiles ( 1 and 2 ) are characterised by a consistent course of both point clouds at locally large distances from the coastline.

- In the coastline areas, a change in the (sand) relief due to the aeolian and hydrological circulation of sand can be noted.

- The middle profiles (2 and 3) are characterised by the UAV point cloud deviation from the reference TLS point cloud adopted as correct. In both cases, the UAV cloud points are located below the TLS cloud.

- The UAV point cloud is characterised by high noise (particularly evident on profile 1) which results from numerical processes generating a cloud from aerial photographs.
- Limited confidence should be placed in the UAV cloud point coordinates, with particular regard to the height coordinate which is affected, apart from the translation error, by the error in relation to the TLS reference cloud.

\section{Conclusions}

Terrestrial laser scanning and photogrammetry techniques are efficient tools for the mass acquisition of geospatial data. Due to the increasing users' demand, the conditions for the availability of measuring instruments are gradually improving. The advantage of terrestrial laser scanners is the millimetre accuracy of the cloud point coordinates under determination. The recording of point clouds may result in the deterioration of accuracy parameters. In many cases, the error of adjustment and fitting of neighbouring point clouds does not exceed single centimetres. In many cases, obtaining a relatively uniform coverage of the analysed object with points requires the use of many sites. This is due to the limited range of distance measurement and to the angle of laser beam incidence on the flat surface of land, which decreases with distance. This inconvenience is not found in point clouds generated on the basis of photographs taken during a photogrammetric flight pass. Flying drones take a series of photographs with partial coverage, and the coordinates of particular points from the cloud are

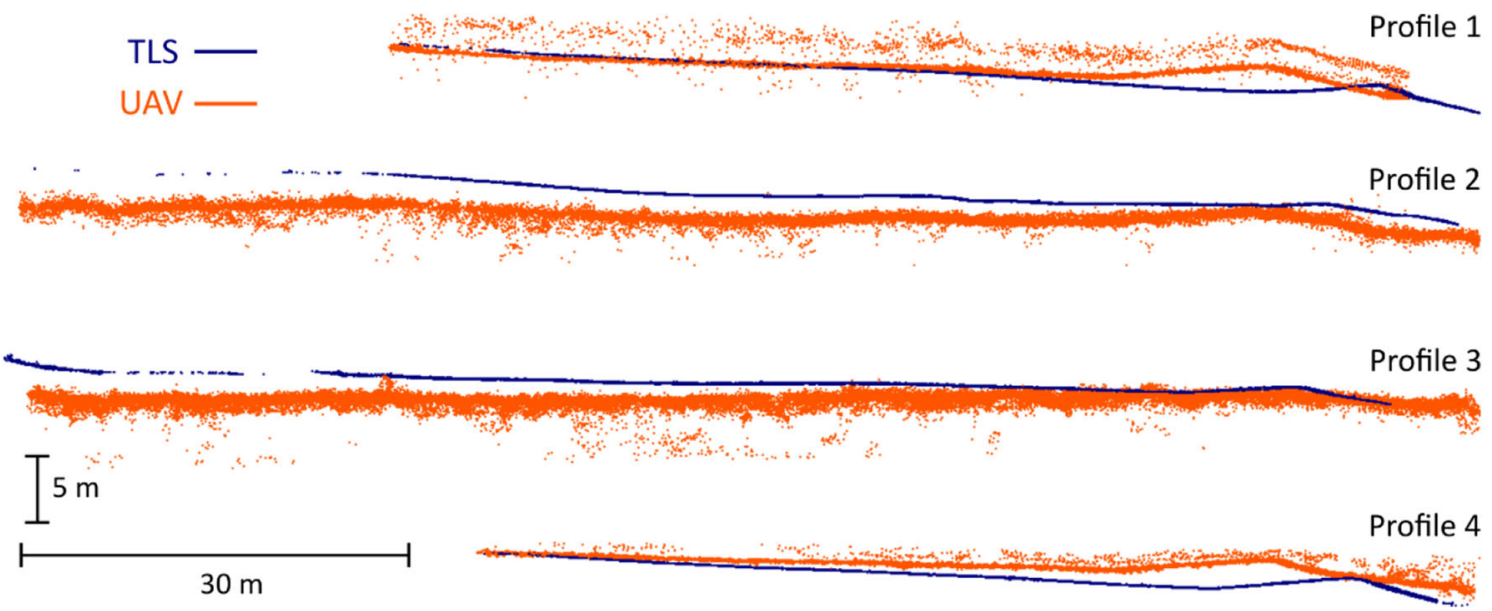

Fig. 10 TLS and UAV: transverse profiles of point clouds 
determined on their basis. In many cases, the clouds generated in this manner contain significant noise, i.e. points which do not reflect any physically occurring objects. In order to eliminate their presence, appropriate filtering algorithms are applied which significantly improve the cloud readability and quality.

This publication contains a description of the comparative analysis of point clouds obtained using terrestrial laser scanner measurements and from a photogrammetric flight pass with a flying drone. A precondition for carrying out the comparison was the mutual data harmonisation which involved the performance of spatial transformations of point clouds to a common coordinate system. To this end, an independent measurement was carried out using a satellite receiver using RTK corrections and ensuring single-centimetre accuracy. Based on the determined coordinates, two point clouds were transformed into a single flat coordinate system and into a single height system. Several-centimetre differences where noted when fitting the laser scanning cloud. The point cloud created on the basis of the photogrammetric model had the georeference; however, it should be noted that the drone GNSS receiver accuracies failed to ensure geometric consistency in relation to the adopted reference coordinates. It was therefore necessary to determine the transformation parameters in the form of rotation angles, translation vector, and the scale factor.

The comparative analysis results indicate a higher reliability of the laser scanning data. The point cloud is accurate and has a small amount of noise, unlike a cloud generated from photographs which has much more noise. The differences in the heights representing the relief between two clouds reached (in a large proportion) $1 \mathrm{~m}$. It is worth stressing that the imaging of a cloud originating from photographs does not have a uniform and smooth course and that points which ambiguously indicate the course of the beach surface are frequently found there. This is particularly noticeable on the transverse profiles drawn perpendicular to the coastline. Hence, both the relief and the coastline course determined on the basis of photogrammetric data should be compared with the results of measurements carried out using higher accuracy methods.

\section{Compliance with ethical standards}

Conflict of interest The authors declare that they have no conflict of interest.

Open Access This article is licensed under a Creative Commons Attribution 4.0 International License, which permits use, sharing, adaptation, distribution and reproduction in any medium or format, as long as you give appropriate credit to the original author(s) and the source, provide a link to the Creative Commons licence, and indicate if changes were made. The images or other third party material in this article are included in the article's Creative Commons licence, unless indicated otherwise in a credit line to the material. If material is not included in the article's Creative Commons licence and your intended use is not permitted by statutory regulation or exceeds the permitted use, you will need to obtain permission directly from the copyright holder. To view a copy of this licence, visit http://creativecommons.org/licenses/by/4.0/.

\section{References}

Ahmed ASM (1997) 2D and 1D numerical model simulations for the effect of a single detached breakwater on the shore. Q1800. 22 Report Delft Hydraulics-IHE. MSc thesis, Delft University of Technology

Berinde VASILE, Pacurar M (2013) The role of the Pompeiu-Hausdorff metric in fixed point theory. Creat Math Inform 22(2):143-150

Dabrowski PS (2019) Accuracy of geopotential models used in smartphone positioning in the territory of Poland. In: IOP Conference Series: Earth and Environmental Science 221(1), p 012080. https://doi.org/10.1088/1755-1315/221/1/012080

Dabrowski P, Specht C (2019) Spatial expansion of the symmetrical objects point clouds to the lateral surface of the cylinder - mathematical model. Measurement 134:40-47. https://doi.org/10.1016/j. measurement.2018.10.036

Donker J, Van Maarseveen M, Ruessink G (2018) Spatio-temporal variations in foredune dynamics determined with mobile laser scanning. J Mar Sci Eng 6(4):126. https://doi.org/10.3390/jmse6040126

Feng Q, Sjögren P, Stephansson O, Jing L (2001) Measuring fracture orientation at exposed rock faces by using a non-reflector total station. Eng Geol 59(1-2):133-146. https://doi.org/10.1016/S00137952(00)00070-3

Fernández-Guisuraga J, Sanz-Ablanedo E, Suárez-Seoane S, Calvo L (2018) Using unmanned aerial vehicles in postfire vegetation survey campaigns through large and heterogeneous areas: opportunities and challenges. Sensors 18(2):586. https://doi.org/10.3390/s18020586

Fritz A, Kattenborn T, Koch B (2013) UAV-based photogrammetric point clouds - tree stem mapping in open stands in comparison to terrestrial laser scanner point clouds. Int Arch Photogramm Remote Sens Spat Inf Sci 40:141-146

Heritage G, Large A (2009) Laser scanning for the environmental sciences. Wiley

Hongoh D, Kajiwara K, Honda Y (2001) Developing ground truth measurement system using RC helicopter and BRDF model in forest area. In 22nd Asian conference on remote sensing, 5, p 9

Ihde J, Adam J, Gurtner W, Harsson BG, Sacher M, Schlüter W, Wöppelmann G (2000) The height solution of the European vertical reference network (EUVN). Veröff. Bayer. Komm. für die Internat. Erdmessung. Astronom Geod Arb 61:132-145

James MR, Chandler JH, Eltner A, Fraser C, Miller PE, Mills JP, Noble T, Robson S, Lane SN (2019) Guidelines on the use of structurefrom-motion photogrammetry in geomorphic research. Earth Surf Process Landf 44:2081-2084. https://doi.org/10.1002/esp.4637

Jiang Q, Fang S, Peng Y, Gong Y, Zhu R, Wu X, Ma Y, Duan B, Liu J (2019) UAV-based biomass estimation for rice-combining spectral, TIN-based structural and meteorological features. Remote Sens 11(7):890. https://doi.org/10.3390/rs11070890

Mayor of the City of Sopot (n.d.). Response to interpellation No. 154/ 2016 of 07.12.2016. Sopot, 20.12.2016 r. (in Polish)

Mikita T, Janata P, Surový P (2016) Forest stand inventory based on combined aerial and terrestrial close-range photogrammetry. Forests 7(8): 165. https://doi.org/10.3390/f7080165

Nesbit PR, Hugenholtz CH (2019) Enhancing UAV-SfM 3D model accuracy in high-relief landscapes by incorporating oblique images. Remote Sens 11(3):239. https://doi.org/10.3390/rs11030239

Specht M, Specht C (2018) Hydrographic survey planning for the determination of territorial sea baseline on the example of selected polish 
sea areas. In: International Multidisciplinary Scientific GeoConference: SGEM: Surveying Geology \& mining Ecology Management, vol 18, p 829-836. https://doi.org/10.5593/ sgem2018/2.2/S09.105

Specht C, Dabrowski P, Dumalski A, Hejbudzka K (2016) Modeling 3D Objects for navigation purposes using laser scanning. TransNav 10(2):301-306. https://doi.org/10.12716/1001.10.02.12

Specht C, Weintrit A, Specht M, Dabrowski P (2017a) Determination of the territorial sea baseline-measurement aspect. In IOP Conference Series: Earth and Environmental Science 95(3):032011. https://doi. org/10.1088/1755-1315/95/3/032011

Specht C, Specht M, Switalski E (2017b) Application of an autonomous, unmanned survey vessel (ASV/USV) in bathymetric measurements. Pol Marit Res 24(3):36-44. https://doi.org/10.1515/pomr-20170088

Specht C, Specht M, Dabrowski P (2017c) Comparative analysis of active geodetic networks in Poland. In: International Multidisciplinary Scientific GeoConference: SGEM: Surveying Geology \& mining Ecology Management, vol 17, p 163-176. https://doi.org/10.5593/ sgem2017/22/S09.021
Stateczny A, Wlodarczyk-Sielicka M, Gronska D, Motyl W (2018) Multibeam Echosounder and LiDAR in process of 360-degree numerical map production for restricted waters with HydroDron. In Proceedings of the 2018 Baltic geodetic congress, Gdańsk, Poland, p 288-292

The Act of March 4, 2010 on spatial dat infrastructure (2010 no 76 pos. 489) (in Polish)

The Institute of Oceanology of the Polish Academy of Sciences (2016) Performing research and modeling works of the bottom and the sea shore near the pier in Sopot, (in Polish)

Urbanski J, Morgas W, Specht C (2008) Perfecting the maritime navigation information services of the European Union. In: Proceedings of the 1 st international conference on information technology. Gdańsk, Poland, p 1-4

Vosselman G, Maas HG (2010) Airborne and terrestrial laser scanning. $\mathrm{CRC}$

Publisher's note Springer Nature remains neutral with regard to jurisdictional claims in published maps and institutional affiliations. 